\title{
Peltomexicanin, a Peltogynoid Quinone Methide from Peltogyne Mexicana Martínez Purple Heartwood
}

\author{
Paulina Gutiérrez-Macías ${ }^{1}$, Javier Peralta-Cruz ${ }^{2}$, Amparo Borja-de-la-Rosa ${ }^{3}$ and \\ Blanca E. Barragán-Huerta ${ }^{1, *}$
}

1 Department of Environmental Systems Engineering, Escuela Nacional de Ciencias Biológicas, Instituto Politécnico Nacional, Av. Wilfrido Massieu S/N, Unidad Profesional Adolfo López Mateos, Gustavo A. Madero, México City CP 07738, Mexico; pau_21_gm@hotmail.com

2 Department of Organic Chemistry, Escuela Nacional de Ciencias Biológicas, Instituto Politécnico Nacional, Prolongación de Carpio y Plan de Ayala, S/N. Miguel Hidalgo, México City CP 11340, Mexico; javierperaltacruz@yahoo.com

3 Division of Science Forestry, Universidad Autónoma Chapingo, Carr. Mexico-Texcoco Km 38.5, Texcoco, México State CP 56230, Mexico; aborja@correo.chapingo.mx

* Correspondence: bbarraganh@ipn.mx or bbarraga59@yahoo.com; Tel.: +52-55-5729-6300 (ext. 52310)

Academic Editor: Marcello Iriti

Received: 17 November 2015; Accepted: 28 January 2016; Published: 4 February 2016

\begin{abstract}
Peltomexicanin (7,10-dihydroxy-6,12-dioxa-5H-tetraphen-3-one) is a new peltogynoid quinone methide isolated from Palo Morado (Peltogyne mexicana Martínez) heartwood by column chromatography. Its chemical structure was elucidated by IR, NMR $\left({ }^{1} \mathrm{H},{ }^{13} \mathrm{C}\right), 2 \mathrm{D}$ NMR experiments (COSY, NOESY, HMQC, and HSQC), ESI-MS, and UV-Vis spectroscopic analysis. According to HPLC quantification, this compound is the main pigment and accounts for $1.21 \%$ of Palo Morado heartwood material. The antioxidant activity of peltomexicanin and dried methanolic extract (DEx) of purple heartwood was evaluated using the radical of 2,2'-azinobis-(3-ethylbenzothiazoline-6-sulphonic acid) (ABTS) assay, and the corresponding values expressed as Trolox equivalents ( $\mu \mathrm{mol} \mathrm{TE} / \mathrm{mg}$ sample) were 4.25 and 4.57 , respectively.
\end{abstract}

Keywords: Peltogyne mexicana Martínez; peltogynoids; quinone methide; purple heartwood; peltomexicanin

\section{Introduction}

Peltogyne mexicana Martínez, commonly known as Palo Morado, is one of the twenty-three species belonging to Caesalpiniaceae family, and it is an endemic tree from Guerrero State, Mexico. The principal characteristic of its heartwood is a particular purple color; native people exploit this attribute and the wood's hardness to elaborate wooden crafts, furniture and souvenirs [1]. Previous studies in other species have shown that the compounds responsible for the color are related to peltogynoids. These compounds are derivatives of flavonoids, with which they share a similar chemical structure; they can found in fruits, barks, roots, and aerial parts from species of the genus Peltogyne, Acacia, Caesalpinia and Cassine, among others [2-8]. The first peltogynol isolated was (+)-peltogynol from P. porphyrocardia Griseb. ex Benth by Robinson and Robinson [9] and its chemical structure was elucidated by Hassall and Weatherston [10]. Peltogynin and mopanin the respective oxidation products of (+)-peltogynol and its isomer, mopanol, were reported by Brandt and Roux [4] and Drewes and Roux [11]. The compounds described in these studies have a chromophoric group in their structure that confers color. In this study, we present the isolation, structural analysis, and quantification of peltomexicanin, a peltogynoid quinone methide from the heartwood of $P$. mexicana. 
Quinone methides are analogous compounds to quinones, wherein a carbonyl oxygen has been replaced by a methylene group. There are three isomers of quinone methides: ortho-, para- and meta-, but the ortho- and para- types are the most common. Also, quinone methides are polar and more reactive than quinone and simple enones (like $\alpha, \beta$-unsaturated ketones). The importance of their study lies in which they are intermediates in chemical and biochemical synthesis reactions [12]. Besides, it has been reported that the ortho-quinone methide moieties confer important biological activities. For example, they have antioxidant properties and they are responsible for the cytotoxic and/or cytoprotective effects of many drugs, natural products, and endogenous compounds [13]. Therefore, the interest on the development of methods for quinone methides synthesis has been increased in the recent years [14], although simple quinone methides, such as, those without substituents at the exocyclic methylene group, are unstable compounds. Because of that, many efforts have been focused on their stabilization, mainly form quinone methide coordination complexes with transition metals [15-17]. To the best of our knowledge, however, none of the peltogynoid quinone methides have yet been characterized.

\section{Results and Discussion}

\subsection{Structural Elucidation of the Isolated Compound}

A purple amorphous powder was obtained, with UV-Vis (MeOH) $\lambda_{\max } \mathrm{nm}(\log \varepsilon) 286 \mathrm{~nm}(3.64)$, $398 \mathrm{~nm}$ (3.42), $530 \mathrm{~nm}$ (3.44) and $566 \mathrm{~nm}$ (3.37); $\lambda_{\max }(+\mathrm{NaOMe}) 288 \mathrm{~nm}$ (3.58), $344 \mathrm{~nm}$ (3.38), $432 \mathrm{~nm}$ (3.46), $616 \mathrm{~nm}$ (3.68); $\lambda_{\max }(+\mathrm{HCl}) 282$ (3.43), $396 \mathrm{~nm}$ (3.05), $536 \mathrm{~nm}$ (3.56). Bands typical of phenolic compounds were observed in the IR spectrum of the pure pigment; these were similar to those observed in compounds related to peltogynoids [18]. We observed a stretch band at $3352 \mathrm{~cm}^{-1}$ characteristic of the O-H bond, two bands of stretching 2970 and $2923 \mathrm{~cm}^{-1}$ for the C-H bond, a signal of a carbonyl group at $1611 \mathrm{~cm}^{-1}$, a band at $1283 \mathrm{~cm}^{-1}$ characteristic of the $-\mathrm{C}-\mathrm{O}-\mathrm{C}=$ group. Aromaticity $(\mathrm{Ar}-\mathrm{H})$ of the compound was represented by an intense band at $883 \mathrm{~cm}^{-1}$. Pigment analysis by ESI-MS in positive mode generated a $[\mathrm{M}+\mathrm{H}]^{+}$ion at $m / z 283.0589,(m / z$ expected 283.0601$)$ in agreement with the molecular formula $\mathrm{C}_{16} \mathrm{H}_{11} \mathrm{O}_{5}$.

Proton NMR exhibited a set of six protons in the aromatic region corresponding to aromatic protons of two independent systems A and B. A COSY experiment revealed a three coupled proton system attributed to H-8 (doublet, 7.94 ppm), H-9 (double doublet 6.25 ppm, J=1, $10 \mathrm{~Hz}$ ) and H-11 (doublet $6.33 \mathrm{ppm}, J=1 \mathrm{~Hz}$ ) in ring A. The three protons for ring B were observed as broad singlets at 7.27 ppm (H-4), $7.16 \mathrm{ppm}(\mathrm{H}-2)$ and $6.66 \mathrm{ppm}(\mathrm{H}-1)$, respectively. Methylene protons for C-5 were observed as a broad singlet at $5.06 \mathrm{ppm}$. Correspondent protonated carbons were attributed based on results from an HSQC experiment (Table 1); carbon shifted at $158.43 \mathrm{ppm}(\mathrm{C}-10)$ was attributed to the ipso-hydroxy group as well as C-11a shifted at $152.58 \mathrm{ppm}$.

Fusion between rings $\mathrm{ABCD}$ was evidenced by long range ${ }^{1} \mathrm{H}^{13} \mathrm{C} \mathrm{HMBC}$ correlation, in ring $\mathrm{A}$ the proton shifted at $6.33 \mathrm{ppm}(\mathrm{H}-11)$ has a three bond correlation with (C-9), proton H-9 ( $\delta 6.25 \mathrm{ppm})$ in the same ring correlated with C-11 ( $\delta 107.52 \mathrm{ppm})$. H-8 was correlated with the carbon located at $152 \mathrm{ppm}$ (C-11a) which is the fused enol ether group of the system. The second hydroxyl group was found in ring $C$ and shifted the corresponding ipso carbon C-7 to 146.06 ppm due its enol character.

Methylene carbon C-5 ( $\delta$ 66.64) was evidenced by ${ }^{13} \mathrm{C}$ attached proton test $(\mathrm{APT})$ analysis, methylene protons correlated with alpha carbon C-4 $(\delta 112.58)$ in ring B. In ring D we observed long range correlations ${ }^{1} \mathrm{H}_{-}{ }^{13} \mathrm{C}$ between the methylene protons $(\delta 5.06 \mathrm{ppm}$ ) with the carbon $\mathrm{C}-7$ (W) and $\mathrm{C}-12 \mathrm{~b}$ belonging to the quinone methide structure conformed by ring $\mathrm{B}$ and ring $\mathrm{D}$ (Figure 1). Two bond ${ }^{1} \mathrm{H}-{ }^{13} \mathrm{C}$ correlation was observed from protons $\mathrm{H}-2$ and $\mathrm{H}-4$ shifted to $7-16$ and $7.27 \mathrm{ppm}$ respectively with the carbonyl group of quinone moiety located at $179.36 \mathrm{ppm}$ in ${ }^{13} \mathrm{C}-\mathrm{NMR}$.

Thus, the structure was established as 7,10-dihydroxy-6,12-dioxa-5H-tetraphen-3-one, due the observed IR, MS and ${ }^{1} \mathrm{H}$ - and ${ }^{13} \mathrm{C}-\mathrm{NMR}$ data. We named the pigment as "peltomexicanin". The proposed structure suggests that peltomexicanin represents a rare peltogynoid quinone methide compound. 
Table 1. ${ }^{1} \mathrm{H}-(500 \mathrm{MHz})$ and ${ }^{13} \mathrm{C}-\mathrm{NMR}(125 \mathrm{MHz})\left(296 \mathrm{~K}\right.$ in methanol- $\left.d_{4}\right)$ spectroscopic assignments for peltomexicanin.

\begin{tabular}{|c|c|c|c|}
\hline Carbon Number & ${ }^{13} \mathrm{C} \delta$ & ${ }^{1} \mathrm{H} \delta$, Multiplicity, $J(\mathrm{~Hz})$ & HMBC ${ }^{1} \mathrm{H}^{-13} \mathrm{C}$ Correlations \\
\hline 1 & 110.94 & $6.66, b r s$ & $\mathrm{C}-12 \mathrm{~b}$ \\
\hline 2 & 108.76 & $7.16, b r s$ & $C-1, C-3, C-12 a$ \\
\hline 3 & 179.36 & & \\
\hline 4 & 112.58 & $7.27, s$ & $\mathrm{C}-3$ \\
\hline $4 a$ & 159.54 & & \\
\hline 5 & 66.64 & $5.06 s$ & $C-4, C-7(W) C-12 a$ C-12b \\
\hline $6 a$ & 113.16 & & \\
\hline 7 & 147.0 & & \\
\hline $7 a$ & 133.47 & & \\
\hline 8 & 131.74 & $7.94, d(10)$ & C-11a, C-10 \\
\hline 9 & 107.52 & $6.26, d d(1,10)$ & C-11 \\
\hline 10 & 158.13 & & \\
\hline 11 & 102.50 & $6.33, d(1)$ & C-9, C-10 \\
\hline $11 \mathrm{a}$ & 152.58 & & \\
\hline $12 \mathrm{a}$ & 146.06 & & \\
\hline $12 b$ & 121.81 & & \\
\hline
\end{tabular}

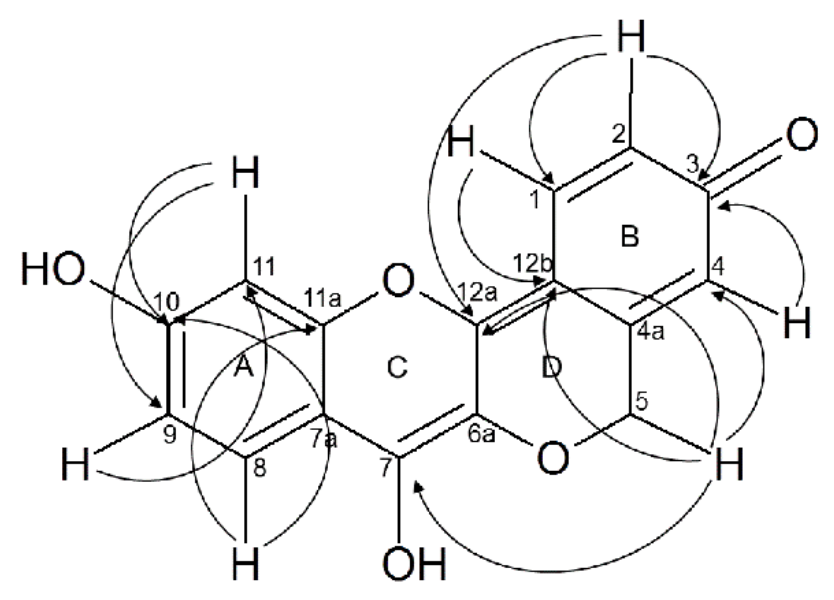

Figure 1. Peltomexicanin, multiple long range correlations observed by HMBC.

Results obtained for pigment analysis by UV-Vis, IR, ESI-MS, and 1D/2D nuclear magnetic resonance techniques confirm that we have isolated a flavonoid not previously reported, which in its enolized form, it has a similar structure to that of peltogynin and mopanin. The molecular weights reported for those compounds are $298.05 \mathrm{~g} / \mathrm{mol}$, whereas the molecular weight determined for peltomexicanin was $282.05 \mathrm{~g} / \mathrm{mol}$, indicating that the pigment from P. mexicana has one less hydroxy group than peltogynin or mopanin.

\subsection{Quantification by HPLC-DAD}

The HPLC chromatogram showed a well-defined peak at $530 \mathrm{~nm}$ for the purified pigment with a retention time of $11.08 \mathrm{~min}$. The peltomexicanin concentration calculated in the semipolar fraction was $11.85 \%$. This represents $9.12 \%$ of the dried extract and $1.21 \%$ of the heartwood of P. mexicana.

\subsection{Antioxidant Activity}

The antioxidant activity of peltomexicanin expressed as Trolox equivalent antioxidant capacity (TEAC) was calculated as $1.20 \pm 0.04 \mathrm{mM}$, which is lower compared to that reported for other flavonoids such as quercetin $($ TEAC $=3.68 \pm 0.12)$ and myricetin $(3.07 \pm 0.23 \mathrm{mM})$ [19]. This may 
be since peltomexicanin differs from those flavonoids in that it contains a fourth ring that blocks the reactive groups, which are usually free in flavonoids. Thus, this structural configuration could result in a reduced ability of the molecule to neutralize radicals.

The specific radical scavenging estimated for peltomexicanin was $4.28 \pm 0.10 \mu \mathrm{mol} \mathrm{TE} / \mathrm{mg}$; this value was slightly lower than $4.57 \pm 0.10 \mu \mathrm{mol} \mathrm{TE} / \mathrm{mg}$ obtained with the dried extract (DEx). This may be attributable to the presence of other compounds in the extract that could increase the antiradical activity alone or synergistically.

In conclusion, we have isolated a new purple pigment from P. mexicana Martinez and identified it as a quinone methide peltogynoid. This compound, named peltomexicanin, showed an important antioxidant activity. This feature lays the groundwork for additional studies of its biological activity.

\section{Experimental}

\subsection{General Procedures}

UV-Vis spectra were obtained using a DR 5000 spectrophotometer (Hach, Loveland, CO, USA) in a range from 230 to $700 \mathrm{~nm}$. The IR spectrum was recorded on a Jasco FT-IR instrument equipped with ATR (Jasco, Easton, MD, USA). The exact molecular mass was obtained by (ESI) analysis on a Bruker micrOTOF-Q II instrument (Bruker Daltonics, Bremen, Germany). Samples were dissolved in methanol and were injected directly to the spectrometer. The capillary potential was $-4.5 \mathrm{kV}$, the dry gas temperature $200{ }^{\circ} \mathrm{C}$ and the drying gas flow $4 \mathrm{~L} / \mathrm{min}$. Total ion chromatograms from $\mathrm{m} / \mathrm{z}$ 50 to 3000 were obtained. MS data were processed using Data analysis 1.0 (Bruker Daltonics). NMR experiments $\left({ }^{1} \mathrm{H}\right.$ at $\left.500 \mathrm{MHz}\right)$ and $\left({ }^{13} \mathrm{C}\right.$ at $\left.125 \mathrm{MHz}\right)$ were performed with Varian 500 equipment (Varian, Palo Alto, CA, USA) using methanol- $d_{4}$ as a solvent and TMS as internal reference.

\subsection{Plant Material}

P. mexicana Martinez (Palo Morado) was collected in Guerrero State $\left(17^{\circ} 09^{\prime} 32^{\prime \prime} \mathrm{N}\right.$ latitude and $99^{\circ} 30^{\prime} 51^{\prime \prime} \mathrm{W}$ longitude). Plant was identified by Post-graduate College of Chapingo, Mexico and a voucher specimen (Registration number 51,392) was deposited at the Herbarium CHAP.

\subsection{Extraction and Isolation}

The heartwood of P. mexicana was crushed into a fine powder and then sieved through US standard testing sieve \#45 to \#100. Particles retained in mesh \#100 $(355 \mu \mathrm{m}<$ particle size $>150 \mu \mathrm{m})$, were extracted in the dark with $\mathrm{MeOH}(1 \% \mathrm{HCl})$ in a solvent: solid ratio of 95:5 $(v / w)$ at $20 \pm 2{ }^{\circ} \mathrm{C}$ for $24 \mathrm{~h}$ in a $250 \mathrm{~mL}$ flask with magnetic stirring. The solution was then filtered and concentrated on a rotatory evaporator (R-200, Büchi, Flawil, Switzerland) at $40{ }^{\circ} \mathrm{C}$. This yielded an amorphous purple powder, which was named "dried extract" (DEx). Prior to purification, DEx was added to a partition liquid-liquid in a system of water-ethyl acetate (EtOAc) in order to remove compounds that were either highly polar or water- and EtOAc-insoluble. One gram of DEx was dissolved in $100 \mathrm{~mL}$ of EtOAc and $30 \mathrm{~mL}$ of distilled water to neutral $\mathrm{pH}$ was added. This solution was mixed vigorously and then organic phase was recovered; the operation was repeated by adding an additional two volumes of water. The organic fraction (corresponding to the semipolar fraction of DEx) was concentrated with a rotatory evaporator at $40{ }^{\circ} \mathrm{C}$. This fraction represented $76.93 \% \pm 1.73 \%$ of DEx.

Subsequently, $600 \mathrm{mg}$ of the semipolar fraction were dissolved in $2.0 \mathrm{~mL}$ of $\mathrm{MeOH}$ and loaded onto a column packed with Sephadex LH-20 (1.5 $\times 35 \mathrm{~cm}$, LH20 Sigma, St. Louis, MO, USA). As eluent, a gradient of $\mathrm{MeOH}: \mathrm{H}_{2} \mathrm{O}$ was used in proportions of 0:10, 1:9, 2:8, 3:7, 4:6, 5:5, 6:4, 7:3, 8:2, 9:1 and 10:0. The pigment fraction of interest was concentrated and dried with a rotary evaporator at $40^{\circ} \mathrm{C}$.

\subsection{Quantification by HPLC-DAD}

Quantification of peltomexicanin pigment in the heartwood was performed by HPLC analysis, using the pure pigment as standard of reference. One milligram of peltomexicanin was diluted in 
$1 \mathrm{~mL}$ of $\mathrm{MeOH}$ at $1,0.8,0.6,0.4$, and $0.2 \mathrm{mg} / \mathrm{mL}$, and filtered with $0.2-\mu \mathrm{m}$ pore nylon acrodisc. Sample $(20 \mu \mathrm{L})$ was injected onto the HPLC-DAD instrument (Infinity 1260 Series, Agilent Technologies, Palo Alto, CA, USA) equipped with a quaternary pump and analyzed by a ZORBAX Eclipse Plus C18 column (Agilent Technologies) 4.6 i.d. $\times 150 \mathrm{~mm}, 5 \mu \mathrm{m}$; with a gradient elution of distilled water (phase A) and acetonitrile (phase B) at a flow of $1 \mathrm{~mL} / \mathrm{min}$, starting at $100 \%$ of phase A for $5 \mathrm{~min}$, reaching $50 \%$ of phase $\mathrm{B}$ in $12 \mathrm{~min}$, and $100 \%$ of phase B in $4 \mathrm{~min}$, maintaining for $3 \mathrm{~min}$ gradient, returning to phase A 100\% in $3 \mathrm{~min}$ and then held for a further $3 \mathrm{~min}$. The oven temperature was set at $25^{\circ} \mathrm{C}$. Chromatographic analysis was monitored at $280 \mathrm{~nm}$ and $530 \mathrm{~nm}$ in DAD channels. A calibration curve was constructed using the area data obtained for each pigment dilution. In parallel, a sample of the semipolar fraction of DEx at $5 \mathrm{mg} / \mathrm{mL}$ was analyzed by HPLC in the same conditions as above, and the corresponding area for peltomexicanin was recorded. Using the external standard method, the peltomexicanin concentration in the extract and in the heartwood was calculated.

\subsection{Antioxidant Activity}

The antioxidant activity of the DEx and the pure peltomexicanin were determined by measuring their capacity to scavenge the pre-formed radical of 2,2'-azinobis-(3-ethylbenzothiazoline-6-sulphonic acid) (ABTS) according to the method described by Rufino et al. [20]. ABTS ${ }^{+}$radical was produced by reacting $50 \mathrm{~mL}$ of $7 \mathrm{mM}$ ABTS (A1888 Sigma) stock solution with $880 \mu \mathrm{L}$ of $140 \mathrm{mM}$ potassium persulfate (379824 Sigma) and allowing the mixture to stand in a dark room at room temperature for $16 \mathrm{~h}$ before use. The $\mathrm{ABTS}^{+}$solution was diluted with methanol to obtain an absorbance of $0.70 \pm 0.04$ at $734 \mathrm{~nm}$. Then, $1.5 \mathrm{~mL}$ of $\mathrm{ABTS}^{+}$radical and $30 \mu \mathrm{L}$ of sample or standard were mixed for $6 \mathrm{~min}$ and final absorbance was measured at $734 \mathrm{~nm}$ on a Hach DR5000UV-Vis spectrophotometer. Calibration was performed with a Trolox (238813 Sigma) stock solution as described above and the results were presented as TEAC.

Supplementary Materials: The following are available online at http:/ /www.mdpi.com/1420-3049/21/2/186/s1.

Acknowledgments: This work was carried out with the financial support of National Council for Science and Technology (CONACYT) Project C.B. 2011-01-169779 and Instituto Politécnico Nacional (Project SIP 2015-1298 and 2015-0134). PGM thanks CONACYT for their award of a scholarship.

Author Contributions: Gutiérrez-Macías performed the isolation and quantification of the compound, also carried out the antioxidant activity assay. Peralta-Cruz performed spectroscopic analysis $\left({ }^{1} \mathrm{H}-\mathrm{NMR},{ }^{13} \mathrm{C}-\mathrm{NMR}, 2 \mathrm{D}-\mathrm{NMR}\right.$, IR, MS). Borja-de-la-Rosa provided a sample of identified plant material. Barragán-Huerta and Peralta-Cruz carried out data analysis and structural elucidation of peltomexicanin. Gutiérrez-Macías, Peralta-Cruz and Barragán-Huerta were involved in the preparation of the manuscript. This study was performed based on the planning of Barragán-Huerta and done under her guidance.

Conflicts of Interest: The authors declare no conflict of interest.

\section{References}

1. Navarro, M.J.; de la Borja, R.A.; Machuca, V.R. Características tecnológicas de la madera de Palo Morado (Peltogyne mexicana Martínez) de Tierra Colorada, Guerrero, México. Rev. Chapingo Ser. Cienc. 2005, 11, 73-82.

2. Drewes, S.E.; Mashimbye, M.J.; Field, J.S.; Ramesar, N. 11,11-Dimethyl-1,3,8,10-tetrahydroxi-9methoxypeltogynan and three pentacyclic triterpenes from Cassine transvaalensis. Phytochemistry 1991, 30, 3490-3493. [CrossRef]

3. Ahmadu, A.; Abdulkarim, A.; Grougnet, R.; Myrianthopoulos, V.; Tillequin, F.; Magiatis, P.; Skaltsounis, A. Two new peltogynoids from Acacia nilotica Delile with kinase inhibitory activity. Planta Med. 2010, 76, 458-460. [CrossRef] [PubMed]

4. Brandt, E.V.; Roux, D.G. Metabolites from the purple heartwood of Mimosoideae I, Acacia peuce F. Muell: The first natural 2,3-cis-peltogynoid. J. Chem. Soc. Perkin Trans. 1 1979, 777, 777-780. [CrossRef]

5. Brandt, E.V.; Ferreira, D.; Roux, D.G. Metabolites from purple heartwood of Mimosoideae. Part 2. Acacia carnei maiden: Isolation, synthesis, and reactions of crombeone. J. Chem. Soc. Perkin Trans. 1 1981, 2, 514-521. [CrossRef] 
6. Brandt, E.V.; Ferreira, D.; Roux, D.G. Metabolites from purple heartwood of Mimosoideae. Part 3. Acacia crombei C.T. White: Structure and Partial Synthesis of Crombein, a Natural Spiropeltogynoid. J. Chem. Soc. Perkin Trans. 1 1981, 7, 1879-1883. [CrossRef]

7. Van Heerden, F.R.; Brandt, E.V.; Ferreira, D.; Roux, D.G. Metabolites from purple heartwoods of the Mimosoideae. Part 4. Acacia fasciculifera F. Muell ex. Benth: Fasciculiferin, Fasciculiferol, and the Synthesis of 7-Aryl and 7-Flavanyl-Peltogynoids. J. Chem. Soc. Perkin Trans. 1 1981, 2483-2490. [CrossRef]

8. McPherson, D.D.; Cordell, G.A.; Soejarto, D.D.; Pezzuto, J.M.; Fong, H.; Havsteen, S. Peltogynoids and homoisoflavonoids from Caesalpinia pulcherrima. Phytochemistry 1983, 22, 2835-2838. [CrossRef]

9. Robinson, G.M.; Robinson, R. Leuco-anthocyanins and Leucoanthocyanidins. Part I. The isolation of peltogynol and its molecular structure. J. Chem. Soc. 1935, 744, 744-752. [CrossRef]

10. Hassall, C.H.; Weatherston, J. The absolute configuration of the leucoanthocyanidin, peltogynol. J. Chem. Soc. 1965, 2844, 2844-2849,. [CrossRef]

11. Drewes, S.E.; Roux, D.G. Isolation of mopanine from Colophospermum mopane and interrelation of flavonoid components of Peltogyne spp. J. Chem. Soc. C Org. 1967, 1407, 1407-1410. [CrossRef]

12. Lukeman, M. Photochemical generation and characterization of quinone methides. In Quinone Methides, 1st ed.; Rokita, S.E., Ed.; Wiley: Hoboken, NJ, USA, 2009; pp. 1-26.

13. Bolton, J.L. Quinone methide bioactivation pathway: Contribution to Toxicity and/or Cytoprotection? Curr. Org. Chem. 2014, 18, 61-69. [CrossRef] [PubMed]

14. Toteva, M.M.; Richard, J.P. The generation and reactions of quinone methides. Adv. Phys. Org. Chem. 2011, 45, 39-91. [PubMed]

15. Amouri, H. Metal-stabilized $o$-quinone methides, thioquinones, and selenoquinones: Trapping important reactive intermediates and beyond. Synlett 2011, 1357, 1357-1369. [CrossRef]

16. Amouri, H.; le Bras, J. Taming reactive phenol tautomers and o-quinone methides with transition metals: A structure-reactivity relationship. Acc. Chem. Res. 2002, 35, 501-510. [CrossRef] [PubMed]

17. Amouri, H.; Besace, Y.; Bras, J.L.; Vaissermann, J. General synthesis, first crystal structure, and reactivity of stable o-quinone methide complexes of Cp* Ir. J. Am. Chem. Soc. 1998, 120, 6171-6172. [CrossRef]

18. Choudhary, M.I.; Nur-E-Alam, M.; Akhtar, F.; Ahmad, S.; Baig, I.; Ondognii, P.; Gombosurengyn, P.; Rahman, A. Five new peltogynoids from underground parts of Iris bungei: A mongolian medicinal plant. Chem. Pharm. Bull. 2001, 49, 1295-1298. [CrossRef] [PubMed]

19. Soobrattee, M.A.; Neergheen, V.S.; Luximon-Ramma, A.; Aruoma, O.I.; Bahorun, T. Phenolics as potential antioxidant therapeutic agents: Mechanism and actions. Mut. Res. 2005, 579, 200-213. [CrossRef] [PubMed]

20. Rufino, M.; Alves, R.E.; de Brito, E.S.; de Morais, S.M.; Sampaio, C.D.G.; Pérez-Jimenez, J.; Saura-Calixto, F.D. Metodologia Científica: Determinação da Atividade Antioxidante Total en Frutas Pela Captura do Radical Livre ABTS ${ }^{+}$. Embrapa Agroind. Trop. Comun. Técn. 2007. Avaliable online: http:/ /ainfo.cnptia.embrapa.br/digital/bitstream/CNPAT/10225/1/Cot_128.pdf (accessed on 3 February 2016).

Sample Availability: Samples of peltomexicanin are available from the authors.

(C) 2016 by the authors; licensee MDPI, Basel, Switzerland. This article is an open access article distributed under the terms and conditions of the Creative Commons by Attribution (CC-BY) license (http://creativecommons.org/licenses/by/4.0/). 